\title{
In Search for Comprehensive Philosophy of Music Education in Ghana
}

\author{
Mawusi Foster Eddison (MPhil) \\ University of Education, Winneba, Ghana
}

DOI: $10.7176 / \mathrm{JEP} / 11-9-21$

Publication date:March $31^{\text {st }} 2020$

One of the critical issues in the philosophy of music involves a study of basic questions regarding understanding music or musical meaning; what music is, how people perceive music in the context of their culture, how cultural perceptions influence music and what is the relationship between music and emotions.

One discipline that is so complex to define is music. Many philosophers and ethnomusicologists did a lot of works in defining music yet the fact still remains that none of these giants was able to holistically define what music really is. Many people have different views and definitions about music. These differences emanate from diverse ethnic and cultural backgrounds. No person defines music better than the one from that particular cultural setting. "Music is an immersive sonic and social phenomenon that is at once both physical and emotional. Communication takes place through the processes of musical creation, performance and response (processes which are by no means discrete from each other), and music carries multiple meanings, communal and individual, intentional and unpredictable. People turn to music every day throughout their lives to create a sense of identity, to connect with others and to express, reflect and change their emotions. Music is a pervasive feature of life. Music engagement both underpins and accompanies many of our day-to-day activities from our earliest years as well as marking the significant moments of individual and collective life." (https://elissamilne.wordpress.com/2010/12/15/defining-music-in-the-national-arts-curriculum-to-conclude/).

This paper focuses on the Philosophy of Music Education like any other discipline and I tried to express my opinion from the Ghanaian cultural perspective.

There are people who define music as pleasant sound that appeals to the ear. However, what sounds pleasant in one cultural setting will possibly be a noise in other setting. Others define music as singing and dancing neglecting very vital constituents of the discipline. In this paper, the definition of music is based on the cultural perception of what music really is to the performers. The definition embedded how the focused setting value music and how their perception influences music.

Just as I agree partly with the above definitions, it is important to look at the definition of Music as "an art of expressing human thoughts and feelings in orderly manner involving, singing, drumming, and body movements. In this definition, poetry even though rhythmic, is not music because it is non-musically aesthetically organized. Poetry therefore serves as text base set to music. Again, language is not music but language can be musically expressed. E.g. drum language in terms of talking drums.

In the above definition, the central issue "expressing of thoughts and feelings" is very paramount in the understanding and defining music in a particular cultural setting. It gives the opportunity to any researcher to find out the meaning of music in relation to general thinking processes and how these are expressed through tonal and aesthetic forms. Quite complex though, however, it is possible to see clearly this concept through the value system of the said setting. In other words what values does the focused setting attached to music. Taking the cultural setting of this paper, I tried to look at why music is valued which expresses the thought process and how this translates into music as the feeling component.

The foundation of any philosophy of music education must answer the question about why music has value. There are many reasons why people value music. These values could be social, religious, educational, economic and socio-political. In Ghana for example, music performed is often grouped into three; occasional, incidental and recreational according to the purpose and event for which it is performed. Ghanaian traditional music is music made up of all musical types that are closely linked to Ghanaian socio-political institutions. There are often cause and effect occurrences of music in the society.

There are music performed that are connected with life cycle events which include birth rites, naming ceremonies, puberty rites, marriage ceremonies and funeral rites. There are others that are linked with sociopolitical institutions like entoolment and destoolment and some others are associated with religious activities for example "Yeve cult practiced in some part of the Volta Region. There are also economic values for music in Ghana as well. 
Nketia (1971), stated that among the Dagombas, for example, before the day dawn every Monday and Friday musicians are ever present to break the silence of the morn with special greetings to their chiefs through songs of praise accompanied with the beating of hourglass drums. This reveals the value for music in the traditional political institutions in Ghana. The feelings people have about chieftaincy is best expressed in musical form. Nketia (1974), again stated that there are similar situations at the court of the Ashanti king where special music was played at various times of the day as well as particular occasions. For example, among the Akans, the presence of certain music types in a chief's court may include his status since it is only paramount chiefs in the Asante kingdom who are permitted to own 'Kete' ensembles. Kete music and Fontomfrom are performed only for the royalty and those connected with chieftaincy institutions.

Partisan politics or democracy has gained deep root in Ghana. Political leaders of yesteryears and today used music extensively to draw their messages home to their constituencies and electorates. In Ghana, it is very common to experience Borborbor or Kpanlogo music performance in a political rally. This is not a normal case in Europe experiencing an orchestra during a political rally; all due to cultural differences. There is no political platform in Ghana that goes without experiencing the presence of music. There are some music composers and artists who aligned themselves to particular political parties and compose special party songs as well as performing at the party rally stages.

In a typical Ghanaian home, performances of household chores are often associated or characterized with expression of music. There are various games, story-telling events, entertainment and relaxation occasions in which fusion of music is no exemption.

One important reason for which Ghanaians value music is promotion of togetherness or social cohesion. Firstly, Music performed in the community promotes togetherness and instills in the people communal spirits. This is evident in the competitive activities of the communal labour among various clans within communities. Similar evidence is seen among the Asafo groups in various ethnic groupings in Ghana. A typical example is the activities of the two Asafo groups of the people of Winneba during the celebration of Aboakyir festival.

People in expressing their communal spirit and togetherness enhance cultural identity. It serves as means of encouraging involvement in collective behavior. Music in the community results in the spontaneous response to group needs and involvement in collective activity. It brings the members of the community both near and far together as a means of strengthening the social bonds that bind them and the values that aspire in their corporate life. In his Opening Address, Prof. J. Anamuah-Mensah, Vice Chancellor, University of Education, Winneba at the $26^{\text {th }}$ Annual INSET/Confab of PATAG at the Community Health Nurses Training School, Winneba, 24-28 August, 2004, cited the vice chancellor of the university of Cape Town, Njabulo Ndbele in a message at a benefit launch concert for the Pan African Society for Musical Arts said that "Music and dance play a major role in building cultural-national identity in the global context". Prof. J. Anamuah-Mensah made it clear when he stated "we live in a society where music is intimately intertwined with our day to day life. Music and dance starts from the time a child is born to the time of death". The Ghanaian experience is exactly the same.

Music serves as extra form of entertainments or introduction to importance events such as outdooring, festivals and funerals. According to Warren (1973), the main aim of folklore is to serve as mechanism for compensation and escape into fantasy thereby validating the Ghanaian culture through the justification of rituals and institutions. Above all, it used to educate the youth in conforming to behavior patterns of the society.

Each ethnic setting tries to develop its own language culture. Language is thought. The real indigenous Ghanaian songs (not adulterated) are organized around events and occurrences of life. They teach both old and little ones the rich culture involving local vocabularies, structure and forms of the language. This rich cultural embodiment is clearly identified in a vast repertoire ranging from simple lullaby to complex dirges. According to Nketia (1974), all sub-Saharan traditions emphasis singing of which Ghana is major stakeholder. Song is regarded as language and is used as an avenue of communication. As many African languages are "tone languages" in which pitch level determines meaning, the melodies and texts rhythms of songs generally follow the intonation contour and rhythms of the song. Melodies are usually organized within a scale of four, five, six, or seven tones. Through song the children's language and vocabulary are developed.

Apart from language development, Ghanaian indigenous music is an oral tradition that aims to transmit culture, values, beliefs and history from generation to generation. Every society preserves her cultural heritage. This could be done by written records or oral communication. Most ethnic beliefs, values, culture and history that we have today came as a result of oral tradition. A very good tool which enhanced and continues to enhance Ghanaian indigenous heritage is the musical culture. For example many young Ghanaians were not born when the Queen of Britain visited Ghana in 1950s but songs composed to welcome her are still sung today to remember the how many Ghanaians felt during the Queen's visit. Again, liberation songs from the tyranny of King Agorkorli of Notsie of the Ewe tribe reminds the new generation of Ewe tribe of what their forefathers went through to gain independence. Yolisa Nompula (2011) in his article published in the South African Journal of Education cited by Sloboda (1985), says that music of oral tradition is not inferior to that which is written - it is just different. 
Ghana is a religiously pluralistic nation. Predominantly, almost all religious activities are characterized by performing music. This value is so critical to Ghanaians that a person can leave one religious activity to another due to absence of music. Religious music inspires the worshippers to express their loyalty to the deity. Music in religious activities in Ghana for that matter Africa plays three major functions: reparation, thanksgiving and petition. Again indigenous Ghanaian music teaches good moral values underlying the necessity of virtuous deeds and denouncing evil activities. The compositions are particularly directed through highlife music and philosophical themes toward correction of individual behavior and transformation of the society. Nketia (1959) stated that African gods are music lovers. The result of this is "is the creation of musical types appropriate for the worship of each god or pantheon of gods, and in the building up of a repertoire of songs and dances through which they can be reached".

Many Ghanaians earn their living through music. There are traditionally indigenous musicians who earned their living by playing in the courts of traditional chiefs and palm-wine bars of old. Even though some may not be giving money for their work in the courts, they enjoyed the pleasure and rewards in kind. Some others earn their living through formalized concerts. There are others who received royalties for their works (compositions). Individual musicians also export their talents to other European countries which in broad perspective brings foreign exchange to the country. "The key participants involved in the collection of royalties are the music authors/composers, publishers, end users of music and royalties collection societies. Collection societies may either be member-owned collection societies, quasi-governmental collection societies and privately-owned collection agencies" (MUSIGA, 2013).

The question of how cultural perceptions influence music is very important. Culture is said to be the way of life of people leaving in the same geographical area. This includes religion, occupation, language, food, marriage, etc. Of course, the definition of music in every setting must take into consideration how these elements of culture influence the discipline. Many philosophers and ethnomusicologist from the west run short of this idea and in the end generalize concepts that are hardly applicable to many of these cultures in Africa and in particular, Ghana.

In a typical culture like ours for example perception of marriage is different from that of the Asian or Eastern cultures hence the type of music performed during these occasions differ from one another. Each culture has its own language contour or "tonality" even with close cultural backgrounds. Whiles one society observes a dirge in a high tone depending on their language contour other may experience it in a low tone. I refer to this as "cultural discrimination". This concept is a process by which different cultures perceive music and determine what to accept as music and what not to accept.

\section{Music Education}

Music education is a field of study associated with the teaching and learning of music. It touches on all domains of learning, including the psychomotor domain (the development of skills), the cognitive domain (the acquisition of knowledge), and, in particular and significant ways, the affective domain, including music appreciation and sensitivity. The meaning of music education is different for every individual. The value of music may be easy to understand and accept as a society, but the next question that must be answered is why should music be taught in schools? In view with the values of music in relation to the culture of a particular setting such as ours, music education needs much attention in order to achieve its maximum use for effective transformation of society. Plato said "I would teach children music, physics and philosophy; but more importantly music; for in the patterns of music and all the arts, are the keys to learning (https://musicaustralia.org.au/discover/musiceducation/).

Music education in any culture must provide all students with the knowledge and information for them to appreciate music. All students, regardless of socio-economic status, physical or intellectual ability, should be offered the opportunity to discover and explore their innate potential as musicians, and to increase these natural capacities through formal music instruction.

The goal of music education should not only to form an appreciation of the music of others, but also encourage children to shape their own unique musical identity, through academic study and performance opportunities. In this regard, every student of music at any level of education must be actively involved in listening, participating and engaging through music. Accordingly, the aims of music education include the development of critically reflective listeners and musical amateurs who possess the understanding and motivation to give music an important place in their lives and the lives of others in their communities.

Music is a universal language regardless of age. Music education must therefore gear towards giving individual an equal opportunity to learn, gain knowledge of and aspire to be the best they are able to be. Teaching music in schools, colleges and universities needs convenient and welcoming environment that is safe, positive, nurturing for effective teaching and learning.

In the basic level of education, music education should be seen as base-board for music literacy through a balance of activities in singing, instrument playing, note reading, improvisation, composition, music listening, 
music history, movement and dance. In other words, music education in Senior High (secondary) levels of education must effectively harmonize and consolidate the curriculum of the basic level music education and further prepare the necessary platform for advance music learning experiences in colleges and the tertiary levels of education. Children at basic level first of all must be helped to acquire a repertoire of music from their respective cultural settings then also those that are alien to them, after which they can progress to music literacy and note reading. This in a sense would enhance active participation and effective involvement in the learning process.

One important thing that worth noting is that in basic level, children must be made active participants in the learning process. The emphasis must be laid on "doing music" rather than "hearing music". Children must be helped to grow "as musicians" than "like musicians". This can be achieved through deliberate hosts of familiar and unfamiliar activities. In this case each activity must be effected as result of the previous attempt. The curriculum must allow individual children to achieve perfection taking into consideration their strengths and weaknesses. Music education as a discipline should therefore be steered by the purpose of crafting independent musicians, capable of performing, evaluating, and creating music. Again, it should also provide enough room for collaborative learning to accomplish musical knowledge that will then translate in the ensemble setting.

In general, music curriculum must help students achieve both an aesthetic and academic understanding of music, as well as, practical music skills. There must be a Standardized Curriculum of Music Education for all levels of education and across all levels of education; the emphasis should be on musicianship. This implies that music education should be given priority in the national curriculum of education.

\section{The Teacher}

The role of the music educator is paramount in the effective teaching of music in schools, colleges and universities. The students' lives become better if and only if the teacher lives up to expectation. The success of the student does not only depend on the quality of repertoire and instruction of the teacher but also consistent and clear goals for both behaviour and music learning targets. Every Music educator must endeavour to support students by predictable routines and clearly communicated goals, within an organized learning environment. This does not come as a magic but competency of the educator. What must be our concern is the question of how qualified is the music educator.

For a successful music education to take place there must be qualified teachers of music. Teachers must have requisite knowledge and skills in music. In other words, teachers need good and effective performance base aesthetically and academically. That does not mean that services of instructors and knowhow of traditional musicians cannot be employed. They could whenever necessary. However, every formal music education must have well trained music teachers to effect the transmission of musical knowledge and skills. Music should be taught by certified professionals who have a comprehensive knowledge of their subject. Teachers should have a wide knowledge of performance practice, history, theory, and should have good communication and organizational skills. An effective music educator is enthusiastic and passionate about music and working with students of all abilities.

According Elliot (2012), music teaching and learning is sometimes misguided, unethical, or "malpracticed." Music educator or facilitator demands more than musical skills and understandings (formal and/or informal) and having practical knowledge and experience. It is stated that abilities and qualities are necessary, however, there are not sufficient for teaching music thoughtfully, wisely, effectively, compassionately, and ethically. In doing so requires teachers to build, update, and maintain a professional philosophy-practice guidance system. Our attention must be drawn to the fact that not every musician who acquired knowledge and skills in music through formal education can teach music in schools, colleges and universities. It is necessary to look for teachers with formal musical knowledge and skills together with pedagogical experiences. Such a teacher should be able to follow rules and expectations for learning and clearly articulate, revisit, and represent a mutual contract of respect, responsibility, safety, honesty, and caring, in the effort to maximize learning and encourage participation. As our culture continues to grow and change, adjustments in our view of the philosophy of music education will necessitate changes in the field of education. Paul Lehman (Madsen, 2000) hinted at this when he wrote that teachers will have to receive more training in psychology, special education, non-traditional instruments and assessment protocols.

Furthermore, a music educator should be able to unearth musical talents of students and optimize their creative musical thinking as independent individual to bring all into a life-long love of music, as a way of thickening appreciation with practical skills and true musicianship. The music educator must in all cost help students create a musically literate society of music consumers, performers and composers for present and the near future. Another issue of much concern to music educators involves a change in the nature of music literacy. This concern is largely driven by the music itself where technology makes it more difficult and less standard to make music. It sends a clear signal to music educators to have paradigm shift in their thinking and delivery. It is therefore clear that the society needs a music teacher that is dynamic and embracing societal and technological changes. "There is no learning without a learner. And there is no meaning without a meaning maker. In order to survive in 
a world of rapid change there is nothing more worth knowing, for any of us, than the continuing process of how to make viable meanings" (Postman and Weingartner, 1969).

What matters now and again is that teachers need to strive for more collaboration with music professionals outside of academia. Music educators may facilitate this collaboration by using electronic media to bring the world to the students when field trips are not possible. Co-teaching between departments in schools can also be a creative way to bring in new perspectives.

\section{Education and Training}

Another important question concerning music educators is what goes into the training of teachers of music Mereku (1999) states "preparing teachers for music education presents a complex set of problems that have been only partially solved, even in the most developed countries. While these problems include some that are shared with other areas of teacher preparation, they also include others that result from the unique nature of music education itself"

Like any other discipline, music education must aim at producing scholars that can apply musical content and pedagogical practices that are innovative, contemporary, and relevant. The curriculum for training music teachers should focus on making them gain the music literary, pedagogical and technological skills that enable them to excel as educators and to help their students achieve their full musical potential. Their training should prepare them to help students develop skills, concepts, and methodologies in music theory, composition, general musicianship, music history, arranging, orchestrating, improvising, conducting, and music performance. Music educators' programmme of study should embed solo performance techniques required for private instrumental or vocal study; vocal and instrumental techniques, and literature related to solo and ensemble performance; and the relationship of music to other disciplines of study.

\section{Summary}

Philosophy of Music Education is a discipline that seeks to answer questions regarding understanding music or musical meaning; what music is, how people perceive music in the context of their culture, how cultural perceptions influence music and what is the relationship between music and emotions.

Many people have different views and definitions about music. These differences came as a result of diverse ethnic and cultural settings and Music is best defined using intrinsic approach in regards to cultural context. The underlying factor to consider in the Philosophy of Music Education in any cultural setting should be the values of music in relation to the culture of the people.

Music education must aim at providing all students regardless of socio-economic status, physical or intellectual ability, equal opportunity to discover and explore their innate potential as musicians, and to increase these natural capacities through formal music instruction.

Generally, music curriculum must help students achieve both an aesthetic and academic understanding of music, as well as, practical music skills. There should be congenial atmosphere for both teachers of music and students for effective teaching and learning process. Music educators must be well trained, taught by certified professionals who have a comprehensive knowledge of their subject to effect the transmission of musical knowledge and skills.

In training music educators, the aim must be producing scholars that can apply musical content and pedagogical practices that are innovative, contemporary, and relevant. Their training should prepare them to help students develop skills, concepts, and methodologies in music theory, composition, general musicianship, music history, arranging, orchestrating, improvising, conducting, and music performance.

Finally, Philosophy of Music Education should embrace and adapt to the changing trends in society, culture and the technological orientation.

\section{REFERENCES}

Amuah I. R etal (2003) Music and Dance for Teacher Training College. KRAMAD Publishers Limited Cape Coast, Ghana.

https://elissamilne.wordpress.com/2010/12/15/defining-music-in-the-national-arts-curriculum-to-conclude/ retrieved 11/01/2016: 10:36 am.

https://musicaustralia.org.au/discover/music-education/ retrieved 11/01/2016: 10:42 am

Aning, B. A. (1974). A history survey of music in Ghana, in History of Ghana. Accra: The American women's association in Ghana.

Arthur, K. (2006). Reminiscence of ManhyiaTete Adowa: An original composition in contemporary idiom based on Adowa music of the Akans of Ghana. (Unpublished MPhil thesis in Music, University of Cape Coast). 
Elliott, D. J., \& Silverman, M. (2012a). Why music matters: Philosophical and cultural perspectives. In R. MacDonald, G. Kreutz, \& L. Mitchell (eds.), Music, health, and wellbeing (pp. 25-39). Oxford: Oxford University Press.

Elliott, D. J., \& Silverman, M. (2012b). Rethinking philosophy, re-viewing musical-emotional experiences. In W. Bowman \& A. L. Frega (eds.), The Oxford handbook of music education philosophy (pp. 37-62). New York: Oxford University Press.

Lehman, P. R. (1995). Why teach music in school? Remarks prepared for the public relations video presentations of the Gemeinheardt Company, Inc., Elkhart, Indiana. University of Ghana, Legon: International Centre of African Music and Dance (ICAMD). 15 $5^{\text {th }} 17^{\text {th }}$ December, 1999.

Mereku C. W. K. (1999) Challenges in implementing the new music and dance syllabus for primary and junior secondary schools in Ghana. Paper presented at the Workshop on Teaching of African Music and Dance:

Musician Union of Ghana (2013). A Comprehensive Study of the Music Sector in Ghana (Draft), pp.31

Nketia, J. H. (1959). African gods and music. In Univeritas. Vol. IV.

Nketia, J. H. (1971). History and organization of music in West Africa, in Essay music and history in Africa. Evanston: Northwestern University Press.

Warren, D. M. (1973). The Akan of Ghana. Accra: Pointer Limited

Yolisa, N. (2011). Exploring the value of African music in education, Valorising the voice of the marginalized. South African Journal of Education, EASA Vol 31:369-380:) 